\title{
Digestibilidade Aparente de Alguns Alimentos Protéicos pela Tilápia do Nilo (Oreochromis niloticus)
}

\author{
Fábio Meurer ${ }^{1 *}$, Carmino Hayashi ${ }^{2}$, Wilson Rogério Boscolo ${ }^{3}$
}

\begin{abstract}
RESUMO - Foi conduzido um ensaio de digestibilidade para determinar os coeficientes de digestibilidade aparente (CD) da matéria seca (MS), energia bruta (EB) e proteína bruta (PB) da farinha de peixe (FP), farinha de vísceras de aves (FV), glúten de milho (GM) e levedura de álcool spray dried (LS) pela tilápia do Nilo, da linhagem tailandesa. Foram utilizados 100 peixes revertidos sexualmente, (peso médio de 37,6 $\pm 5,0 \mathrm{~g}$ ) acondicionados em dois tanques de alimentação de $500 \mathrm{~L}$ e duas cubas cilíndricas com fundo cônico, de $150 \mathrm{~L}$, para coleta de fezes. A determinação dos $\mathrm{CD}$ foi feita por intermédio da metodologia indireta, tendo sido utilizado $0,1 \%$ de óxido crômico $\left(\mathrm{Cr}_{2} \mathrm{O}_{3}\right)$, como indicador. As médias de temperatura, oxigênio dissolvido, $\mathrm{pH}$ e condutividade elétrica durante o período experimental foram de $25,8 \pm 1,0^{\circ} \mathrm{C} ; 3,2 \pm 1,4 \mathrm{mg} / \mathrm{L} ; 6,8 \pm 0,1 ;$ e $205,7 \pm 16,6 \mu \mathrm{S} / \mathrm{cm}$, respectivamente. Os CD da PB, EB e MS foram respectivamente de 90,66; 89,53 e 87,63 para FP; 82,03; 72,09 e 62,21 para FV; 97,61; 93,52 e 91,01 para GM; 77,39; 62,77 e 58,68 para LS. Os valores de proteína (\%) e energia (kcal/kg) digestíveis, na matéria natural, de 53,01 e 3568,0 para FP; 47,65 e 3650,9 para FV; 65,34 e 5036,7 para GM e 32,19 e 2706,9 para LS.
\end{abstract}

Palavras-chave: digestibilidade, nutrição, proteína, tilápia, Oreochromis niloticus

\section{Apparent Digestibility of Some Protein Sources for Nile Tilapia (Oreochromis niloticus)}

\begin{abstract}
A digestibility trial was carried out to determine the dry matter (MS), gross energy (EB) and crude protein (PB) apparent digestibility coefficients (CD) for fish meal (FP), poultry by-products meal (FV), gluten meal (GM) and alchool spray dried yeast (LV) for Thai Nile tilapia fingerlings. A hundred sexually reverted fishes (average weight $37.6 \pm 5.0 \mathrm{~g}$ ) were assigned to two 500-L feeding tanks and two 150-L cylindrical tanks with conical bottom, to feces collection. CD analysis was performed by the indirect method, using $0.1 \%$ chromic oxide $\left(\mathrm{Cr}_{2} \mathrm{O}_{3}\right)$, as marker. Average water temperature, dissolved oxygen, $\mathrm{pH}$ and conductivity were 25.8 $\pm 1.0^{\circ} \mathrm{C} ; 3.2 \pm 1.4 \mathrm{mg} / \mathrm{L} ; 6.8 \pm 0.1$; and $205.7 \pm 16.5 \mu \mathrm{S} / \mathrm{cm}$, respectively. CD of PB, EB and MS were 90.66, 89.53 and 87.63 for FP; 82.03, 72.09 and 62.21 for FV; 97.61, 93.52 and 91.01 for GM; 77.39, 62.77 and 58.68 for LS, respectively. The digestible values of protein (\%) and energy (kcal/kg), as fed basis, were 53.01 and 3568.0 for FP; 47.65 and 3650.9 for FV; 65.34 and 5036.7 for GM; and 32.19 and 2706.9 for LS.
\end{abstract}

Key Words: digestibility, foods, Oreochromis niloticus, protein, tilapia

\section{Introdução}

A tilápia do Nilo (Oreochromis niloticus) é uma espécie de grande interesse na piscicultura atual, pois é o segundo grupo de peixes de água doce cultivado no mundo, ficando atrás apenas das carpas (Lovshin, 1997; Alceste \& Jorry, 1998). No Brasil, passa a ser a espécie mais cultivada, respondendo por cerca da metade da produção anual de peixes cultivados (Lovshin \& Cyrino, 1998).

O destaque alcançado por esta espécie advém de suas qualidades, como rusticidade (Hayashi, 1995), respostas às condições ambientais adversas como baixo nível de oxigênio e altos níveis de amônia dissolvidos na água (Alceste \& Jorry, 1998), rápido crescimento, boa conversão alimentar e consumo de ração artificial desde a fase larval (Meurer et al., 2000). Sobressai-se também por adequar-se à indústria de filetagem, devido à ausência de espinhos musculares em "Y"; ter ótima aceitação no mercado consumidor, pelas características organolépticas de seu filé; e mostrar-se bastante apreciada nos pesque-pague.

\footnotetext{
1 Zootecnista, MSc., professor dos cursos de Medicina Veterinária e Biologia do Centro de Ciências, Tecnologia e Produção da Pontifícia Universidade Católica do Paraná (PUCPR), Campus de Toledo, Av. da União, n.500, Jardim Coopagro, CEP: 85902-532, Toledo - PR. E.mail: fabiomeurer@pop.com.br

2 Professor Titular do Departamento de Biologia - UEM. E.mail: chayashi@uem.br

3 Zootecnista, Dr., Professor de Engenharia de Pesca/UNIOESTE. E.mail: wrboscolo@bol.com.br

* Parte da dissertação de mestrado do primeiro autor.
} 
Os alimentos protéicos são responsáveis pela maior fração dos custos da ração na piscicultura intensiva e semi-intensiva (Boscolo et al., 2001), pois, além de comporem grande quantidade nas formulações (Kikuchi, 1999), apresentam maior custo que os alimentos energéticos. Alimentos protéicos alternativos à farinha de peixe têm sido estudados com o objetivo de diminuir o custo das rações aquícolas (Oliveira et al., 1997; Refstie et al., 1999; Booth et al., 2001; Siddhuraju \& Becker, 2001); entretanto, um dos problemas encontrados para o uso destes materiais é a falta de informação dos valores de digestibilidade de seus nutrientes (Mukhopadhyay \& Ray, 1997).

A digestibilidade é um dos aspectos mais importantes na avaliação dos alimentos (Pezzato et al., 1988a; Sadiku \& Jauncey, 1995; Degani et al., 1997a) quanto a sua eficiência biológica (Hanley, 1987). O valor nutricional dos alimentos baseia-se não somente na composição química, mas também na quantidade de nutrientes e de energia que o peixe pode absorver e utilizar (NRC, 1993).

Para a expressão do potencial produtivo desejado de uma espécie, é necessária uma ração adequada às exigências nutricionais (Meurer et al., 2002) determinadas, preferencialmente, na forma de nutrientes digestíveis. Várias metodologias podem ser utilizadas na determinação da digestibilidade de alimentos (Barros et al., 1988; Pezzato et al., 1988a; Pezzato et al., 1988b; Hanley, 1987; NRC, 1993; Dimes \& Haard, 1994; Degani et al., 1997a, Carter et al., 1999, Boscolo et al., 2002); entretanto a metodologia indireta com o uso de marcador inerte é preferido à direta, tendo em vista as dificuldades na determinação da quantidade total da ração ingerida e das fezes excretadas no meio aquático (De La Noüe \& Choubert, 1986; Zimmermann \& Jost, 1998; Morales et al., 1999).

A farinha de peixe, de acordo com El-Sayed (1999), é um alimento com alto valor protéico, boa fonte de ácidos graxos essenciais, energia digestível, minerais e vitaminas. Entretanto, Boscolo et al. (2001) relataram existirem dificuldades em se conseguir farinhas de boa qualidade. A farinha de vísceras de aves (FV), da mesma maneira que a FP, é um alimento de composição bastante variável e com alta percentagem de cinzas (Hardy, 1996), pois depende da percentagem de inclusão de penas e outras partes como pés, cabeças, carcaças e restos de produção de filés.

O glúten de milho (GM) é um alimento resultante da retirada do amido do grão de milho; tem composi- ção variável em consequiência do método de extração (Kubitza, 1997). A levedura spray dried (LS) é um material produzido pela indústria sucro-alcooleira, composta por células de levedura (Saccharomyces sp.) obtidas da fermentação do caldo da cana-de-açúcar no processo de produção do álcool (Scapinello, et al., 1996), pelo processo da secagem por spray-dryer. Tem a sua composição química bastante variável em função do método de obtenção, lavagem e secagem (Scapinello et al., 1997). Entretanto, cerca de 20 a $30 \%$ do nitrogênio total pode advir de nitrogênio não protéico, como os ácidos nucléicos (Butolo, 1997), podendo ser fonte de super-estimativa dos valores dos valores protéicos (Meurer et al., 2000).

O objetivo do presente trabalho foi determinar a digestibilidade aparente da proteína bruta, energia bruta e matéria seca da farinha de peixe, da farinha de vísceras de aves, do glúten de milho e da levedura de álcool spray dried, pelo método indireto, com a utilização do óxido crômico como indicador e coleta de fezes por sedimentação.

\section{Materiais e Métodos}

O experimento foi conduzido de março a maio de 2000, no Laboratório de Aquicultura, do Departamento de Biologia, da Universidade Estadual de Maringá. Foram utilizados 100 juvenis de tilápia do Nilo $(O$. niloticus) de linhagem tailandesa, revertidas sexualmente na fase inicial, com peso vivo médio de $37,6 \pm 5,0 \mathrm{~g}$.

A estrutura física utilizada consistiu de dois tanques retangulares em concreto, de $500 \mathrm{~L}$ de volume útil, duas cubas cilíndricas de fundo cônico de 150 L de volume útil, fabricadas em fibra de vidro, onde no fundo possuía uma válvula de PVC, adaptada a um recipiente para coleta de fezes, e dois tanques rede de malha plástica de $1 \mathrm{~cm}$ com cerca de $100 \mathrm{~L}$ de volume interno.

O sistema de oxigenação da água era composto de um compressor volumétrico de ciclo alternativo movido por motor elétrico de $1 / 2 \mathrm{cv}$ ligado por meio de mangueiras plásticas a pedras microporosas, nas caixas e nas cubas. Por segurança, também havia outro sistema de aeração, com mini-compressores elétricos (para aquário) de duas saídas ligados permanentemente. Dois aquecedores de $100 \mathrm{~W}$ estavam disponíveis por caixa para manutenção da temperatura da água.

As variáveis físico-químicas da água, $\mathrm{pH}$, condutividade e oxigênio dissolvido foram monitoradas três vezes por semana, das caixas e cubas; a tempe- 
ratura foi medida diariamente, às 8 h30 e 16h30.

A determinação da digestibilidade aparente dos alimentos testados foi feita de acordo com o NRC (1993) pelo método indireto de coleta de fezes utilizando $0,1 \%$ de óxido crômico $\left(\mathrm{Cr}_{2} \mathrm{O}_{3}\right)$ como indicador, adicionado à ração-referência e às rações-teste (Tabela 1). As rações-teste foram compostas por $70 \%$ da ração-referência e $30 \%$ do alimento a ser testado, corrigindo-se apenas a quantidade de suplemento mineral e vitamínico e sal comum.

Para confecção da ração-referência e das rações-teste, os componentes desta e os alimentos testados foram moídos em triturador tipo faca, com peneira de 0,5 mm (Hayashi et al., 1999). Posteriormente, foram misturados de acordo com a sua formulação e, então, peletizados. A peletização foi feita manualmente em máquina de "moer carne" pelo umedecimento prévio da mistura com água a $50^{\circ} \mathrm{C}$. Após peletização, estas foram secas em estufa de ventilação forçada por 24 horas.

Para coleta das fezes, distribuíram-se os peixes nos dois tanques-rede colocados dentro dos tanques de concreto, denominados de tanque de alimentação, onde permaneceram durante todo o período de adaptação às rações e apenas durante o dia no período de coleta de fezes. As cubas de coleta de fezes foram utilizadas durante o período de coleta, executado durante a noite.

O período de adaptação utilizado para cada ração foi de cinco dias (Degani et al., 1997a), onde os peixes permaneciam sempre na caixa de alimentação sendo arraçoados à vontade, cinco vezes ao dia, duas vezes pela manhã e três à tarde. Durante este período, os tanques de alimentação eram sifonados duas vezes ao dia para retirada de fezes e restos de ração, com renovação diária de $50 \%$ do volume total de água.

No período de coleta de fezes, os peixes foram mantidos durante o dia nos tanques-rede, dentro dos tanques de alimentação, onde foram arraçoados à vontade, duas vezes pela manhã, às $8 \mathrm{~h} 30$ e $11 \mathrm{~h}$, e à tarde, às 13h30; das $16 \mathrm{~h}$ às $18 \mathrm{~h} 30$ eram arraçoados a cada 30 minutos. Após 15 minutos da última refeição, os peixes eram transferidos para os tanques de coleta, onde permaneciam nos tanques de coleta das $18 \mathrm{~h} 45$ às $7 \mathrm{~h} 30$ da manhã seguinte, quando voltavam para o tanque de alimentação.

Com o objetivo de evitar a ingestão de excretas ou restos de ração do fundo dos tanques de alimentação e cubas de coleta de fezes, os peixes foram acondicionados dentro de tanques-rede.
Tabela 1 - Composição percentual das rações-referência e teste, utilizadas para a determinação dos coeficientes de digestibilidade aparente dos alimentos para a tilápia do Nilo

Table 1 - Percentile composition of reference and test diets utilized for feed apparent digestible coefficient of determination for Nile tilapia

\begin{tabular}{lcc}
\hline $\begin{array}{l}\text { Alimento } \\
\text { (Food) }\end{array}$ & $\begin{array}{c}\text { Ração-referência 1 } \\
\text { Reference diet 1 }\end{array}$ & $\begin{array}{c}\text { Ração-teste } \\
\text { Test diet }\end{array}$ \\
\hline $\begin{array}{l}\text { Albumina } \\
\text { Albumin }\end{array}$ & 32,00 & 22,40 \\
$\begin{array}{l}\text { Gelatina } \\
\text { Gelatin }\end{array}$ & 7,70 & 5,39 \\
$\begin{array}{l}\text { Antioxidante BHT } \\
\text { Antioxidant BHT }\end{array}$ & 0,02 & 0,01 \\
$\begin{array}{l}\text { Amido de milho } \\
\text { Corn starch } \\
\text { Celulose }\end{array}$ & 44,18 & 30,93 \\
$\begin{array}{l}\text { Cellulose } \\
\text { Fosfato bicálcico } \\
\text { Dicalcium phosphate } \\
\begin{array}{l}\text { Óleo de soja } \\
\text { Soybean oil }\end{array}\end{array}$ & 6,00 & 4,20 \\
$\begin{array}{l}\text { Suplemento (min + vit) } \\
\text { Supplement (min.+ vit) }\end{array}$ & 3,00 & 2,10 \\
$\begin{array}{l}\text { Sal } \\
\text { Salt }\end{array}$ & 0,50 & 4,20 \\
$\begin{array}{l}\text { Óxido crômico } \\
\text { Chromic oxide }\end{array}$ & 0,50 & 0,50 \\
$\begin{array}{l}\text { Alimento teste } \\
\text { Test food }\end{array}$ & 0,10 & 0,50 \\
Total & 0,00 & 0,10 \\
\hline
\end{tabular}

${ }^{1}$ Níveis de garantia por quilograma do produto (Supremais): Vit. A, 1.200.000UI; Vit. $D_{3}, 200.000 \mathrm{UI}$; Vit. E, $12.000 \mathrm{mg}$; Vit. K3, $2.400 \mathrm{mg}$; Vit. B1 , 4.800 mg; Vit. B2, 4.800 mg; Vit. B6, 4.000mg; Vit. B12, $4.800 \mathrm{mg}$; Ác. Fólico, $1.200 \mathrm{mg}$; Pantotenato Ca, $12.000 \mathrm{mg}$; Vit. C, 48.000mg; Biotina, 48mg; Colina, $65.000 \mathrm{mg}$; Niacina, $24.000 \mathrm{mg}$; Ferro, $10.000 \mathrm{mg}$; Cobre, $6.000 \mathrm{mg}$; Manganês, $4.000 \mathrm{mg}$;Zinco, $6.000 \mathrm{mg}$; lodo, $20 \mathrm{mg}$; Cobalto, $2 \mathrm{mg}$; Selênio, $20 \mathrm{mg}$.

${ }^{1}$ Guarantee levels per kilogram of product (Supremais): Vit. A, 1, 200,000 UI; Vit. $D_{3}, 200,000$ Ul; Vit. E, 12,000 mg; Vit. K3, 2,400 mg; Vit. B1, 4,800 mg; Vit. B2, 4,800 mg; Vit. B6, 4,000 mg; Vit. B12, 4,800 mg; Folic acid, 1,200 mg; Pantotenate Ca, 12,000 mg; Vit. C, 48,000 mg; Biotin, 48,000 mg; Cholin, 65,000 mg; Niacin, 24,000 mg; Fe, 10,000 mg; Cu, 6,000 mg; Mn, 4,000 mg; Zn, 6,000 mg; l, 20 mg; Co, 2 mg; Se, 20 mg.

Após a retirada do tanque-rede, a válvula das cubas coletoras era fechada; então, os copos coletores eram desconectados e as fezes acondicionadas em recipientes plásticos e armazenados sob refrigeração. As águas das cubas eram renovadas apenas uma vez ao dia, quando os seus conteúdos eram totalmente substituídos. A coleta de fezes foi feita por um período de três dias, e antes de reiniciar o processo com outra ração, os peixes passavam um dia em jejum. 
Para as análises químicas, os alimentos e as rações foram descongelados e moídos. As fezes, entretanto, foram descongeladas, secas em estufa de ventilação forçada $\left(55^{\circ} \mathrm{C}\right.$, durante 24 horas $)$, peneiradas e retiradas as escamas, para então serem moídas.

As análises químicas das fezes, rações e alimentos, quanto aos valores de matéria seca (MS), proteína bruta (PB) e energia bruta (EB), foram feitas no Laboratório de Análises de Alimentos do Departamento de Zootecnia da Universidade Estadual de Maringá, de acordo com a metodologia de Silva (1990). A determinação da concentração do cromo, foi realizada no Laboratório de Solos do Departamento de Agronomia da Universidade Estadual de Maringá, por espectrofotometria de absorção atômica (Kimura \& Miller, 1957). Para determinação da energia bruta das fezes, rações e alimentos, foi utilizada uma bomba calorimétrica da marca PARR.

O cálculo dos coeficientes de digestibilidade aparente da matéria seca, proteína e energia brutas da farinha de peixe, farinha de vísceras, de glúten de milho e levedura spray dried foram feitos de acordo com as equações utilizadas por Mukhopadhyay \& Ray (1997):

$$
\begin{aligned}
& \text { Dtd }=100-100\left(\frac{\% I d}{\% I f}\right) \\
& \text { Dand }=100-100\left(\frac{\% I d}{\% I f} \times \frac{\% N f}{\% N d}\right) \\
& \text { Dams }=\frac{100}{\% \text { ing }}\left(\text { Dtdtes }-\frac{\% d r e f}{100} \times \text { Dtdref }\right) \\
& \text { Daning }=\frac{100}{\% \text { ing }}\left(\text { Dandtes }-\frac{\% \text { dref }}{100} \times \text { Dandref }\right)
\end{aligned}
$$

em que $D t d$ é a digestibilidade total da dieta referência e da dieta teste (\%); Dand, a digestibilidade aparente dos nutrientes nas dietas referências e teste $(\%) ; I d$, o indicador na dieta; If, o indicador nas fezes; $N f$, o nutriente nas fezes; $N d$, o nutriente na dieta; Dams, a digestibilidade aparente da matéria seca do ingrediente; Dtdtes, a digestibilidade total da dieta teste; dref, a dieta referência; Dtdref, a digestibilidade total da dieta referência; Daning, a digestibilidade aparente do nutriente do ingrediente; Dandtes, a digestibilidade do nutriente da dieta teste; Dandref, a digetibilidade do nutriente da dieta referência.

\section{Resultados e Discussão}

Os valores médios de temperatura, $\mathrm{pH}$, oxigênio dissolvido e condutividade elétrica, da água das caixas e cubas, durante o período experimental, foram de $25,8 \pm 1,0^{\circ} \mathrm{C} ; 6,8 \pm 0,1 ; 3,2 \pm 1,4 \mathrm{mg} / \mathrm{L}$ e $205,7 \pm$ $16,6 \mu \mathrm{S} / \mathrm{cm}$, respectivamente, os quais estão dentro dos valores recomendados para a espécie (Boyd, 1990; Popma \& Phelps, 1998).

Os resultados da análise dos alimentos testados estão apresentados na Tabela 2 e seus coeficientes de digestibilidade aparente da matéria seca, proteína bruta e energia bruta, na Tabela 3. Os valores dos nutrientes e energia digestíveis dos alimentos estão na Tabela 4.

A farinha de peixe (FP) utilizada no presente experimento é de fabricação nacional, feita a partir de restos de pescado, possuindo valores de $63,21 \%$ de PB e $4308 \mathrm{kcal} / \mathrm{kg}$ de EB na MS. Valores estes que estão entre os encontrados na literatura para FP (Pezzato et al., 1988b; Nengas et al., 1995; Gaylord \& Gatlin, 1996; Degani et al., 1997a; Aksnes \& Opstvedet, 1998; Sugiura, et al., 1998; Rostagno et al., 2000). A farinha de vísceras (FV) utilizada foi fabricada na região de Maringá-PR e continha $62,21 \%$ e $5423 \mathrm{kcal} / \mathrm{kg}$, de PB e EB na MS, respectivamente. Esta composição também se encontra-se dentro valores apresentados pela literatura (Hanley, 1987; Gaylord \& Gatlin, 1996; Degani et al., 1997a; Sugiura, et al., 1998; Rostagno et al., 2000).

Tabela 2 - Proteína bruta (PB), energia bruta (EB) e matéria seca (MS) dos quatro alimentos avaliados

Table 2 - Crude protein (PB), gross energy (EB) and dry matter (MS) of the four evaluated feedstuffs

\begin{tabular}{lccc}
\hline $\begin{array}{l}\text { Alimento } \\
\text { Food }\end{array}$ & $\begin{array}{c}\mathrm{MS} \\
(\%)\end{array}$ & $\begin{array}{c}\mathrm{PB} \\
(\%)\end{array}$ & $\begin{array}{c}\mathrm{EB} \\
(\mathrm{kcal} / \mathrm{kg})\end{array}$ \\
\hline $\begin{array}{l}\text { Levedura spray dried } \\
\text { Spray dried yeast }\end{array}$ & 92,35 & 41,59 & 4312,30 \\
$\begin{array}{l}\text { Glúten de milho } \\
\text { Maize gluten } \\
\text { Farinha de peixe }\end{array}$ & 93,15 & 66,94 & 5385,87 \\
$\begin{array}{l}\text { Fish meal } \\
\begin{array}{l}\text { Farinha de vísceras } \\
\text { Poultrymeal }\end{array}\end{array}$ & 92,50 & 58,47 & 3984,83 \\
& 93,38 & 58,09 & 5063,93 \\
& & & \\
\end{tabular}


A composição do glúten de milho (GM) avaliado, $71,86 \%$ e $5782 \mathrm{kcal} / \mathrm{kg}$, respectivamente, para $\mathrm{PB}$ e EB na MS estão de acordo com os valores apresentados por Gomes et al. (1995), Nengas et al. (1995), Masumoto et al. (1996), Robaina et al. (1997) e Rostagno et al. (2000). O conteúdo de PB e EB da levedura spray dried (LS) testada foi de $41,59 \%$ e $4312 \mathrm{kcal} / \mathrm{kg}$, respectivamente. Estes mostraram-se semelhantes aos valores encontrados por Barros et al. (1988), Butolo (1997), Pacheco (1997), Rossel (1997), Scapinello et al. (1997) e Rostagno et al. (2000).

Tabela 3 - Coeficiente de digestibilidade aparente dos quatro alimentos avaliados

Table 3 - Apparent digestibility coefficients of the four evaluated feedstuffs foods

\begin{tabular}{llcr}
\hline $\begin{array}{l}\text { Flimento } \\
\text { Food }\end{array}$ & \multicolumn{3}{c}{$\begin{array}{c}\text { Coeficiente de digestibilidade } \\
\text { aparente }\end{array}$} \\
& \multicolumn{2}{c}{ Apparent digestibility coefficients } \\
\cline { 2 - 4 } & $\mathrm{PB}$ & $\mathrm{EB}$ & $\mathrm{MS}$ \\
\hline $\begin{array}{l}\text { Levedura spray dried } \\
\text { Spray dried yeast }\end{array}$ & 77,39 & 62,77 & 58,68 \\
$\begin{array}{l}\text { Glúten de milho } \\
\text { Maize gluten }\end{array}$ & 97,61 & 93,52 & 91,01 \\
$\begin{array}{l}\text { Farinha de peixe } \\
\text { Fish meal }\end{array}$ & 90,66 & 89,53 & 87,63 \\
$\begin{array}{l}\text { Farinha de vísceras } \\
\text { Poultry meal }\end{array}$ & 82,03 & 72,09 & 62,21 \\
\hline
\end{tabular}

Tabela 4 - Proteína digestível (PD), energia digestível (ED) e matéria seca digestível (MSD) dos quatro alimentos avaliados

Table 4 - Digestible protein (PD), digestible energy (ED) and digestible dry matter (MSD) of the four evaluated feedstuffs

\begin{tabular}{lccc}
\hline $\begin{array}{l}\text { Alimento } \\
\text { Food }\end{array}$ & $\begin{array}{c}\text { MSD } \\
(\%)\end{array}$ & $\mathrm{PD}(\%)^{1}$ & $\begin{array}{c}\mathrm{ED}^{1} \\
(\mathrm{kcal} / \mathrm{kg})\end{array}$ \\
\hline $\begin{array}{l}\text { Levedura spray dried } \\
\text { Spray dried yeast }\end{array}$ & 58,68 & 32,19 & 2707 \\
$\begin{array}{l}\text { Glúten de milho } \\
\text { Maize gluten }\end{array}$ & 91,01 & 65,34 & 5037 \\
$\begin{array}{l}\text { Farinha de peixe } \\
\text { Fish meal }\end{array}$ & 87,63 & 53,01 & 3568 \\
$\begin{array}{l}\text { Farinha de vísceras } \\
\text { Poultry meal }\end{array}$ & 62,21 & 47,65 & 3651 \\
\hline
\end{tabular}

1 Com base na matéria natural.

${ }^{1}$ As fed basis.

R. Bras. Zootec., v.32, n.6, p.1801-1809, 2003 (Supl. 2)
Os valores dos coeficientes de digestibilidade aparente (CD), da PB, EB e MS, dos alimentos avaliados com os valores da literatura, apresentam-se na Tabela 5 .

Notam-se diferenças entre os valores de digestibilidade aparente dos alimentos para outras espécies em relação à estudada no presente experimento. Este fato corrobora Degani \& Revach (1991), cujas diferenças se devem às variações na fisiologia digestiva das espécies. Uma das vantagens da tilápia do Nilo em relação às outras espécies é que esta se encontra numa posição privilegiada da cadeia alimentar, sendo uma espécie de hábito alimentar onívoro, tem boa capacidade digestiva de alimentos de origem animal e vegetal.

É de grande valor prático a determinação dos valores de digestibilidade aparente dos nutrientes e a energia digestível dos mais variados alimentos para as principais espécies de peixes comercialmente cultivadas. Tais resultados possibilitarão a determinação das exigências nutricionais, com base em nutrientes digestíveis, para a formulação de rações com melhor qualidade nutritiva e ótimo desempenho produtivo.

Como o presente trabalho visou apenas a determinação da digestibilidade aparente de alguns alimentos protéicos para a tilápia do Nilo, não se realizou a comparação estatistica da digestibilidade dos alimentos. No entanto, considerando-se apenas as diferenças numéricas, pode-se notar a ótima digestibilidade do GM em todos os parâmetros mensurados, seguido pela FP, também bastante digestível. A FV apresentou boa digestibilidade apenas da proteína e regular da MS e energia digestível. Finalmente, a LS apresentou digestibilidade apenas regular dos itens avaliados.

O GM é uma fonte protéica com ótimo potencial de utilização para a tilápia do Nilo, basicamente em função dos altos valores PD, ED e MSD, determinados no presente experimento. Os baixos teores de fibra bruta, fibra em detergente neutro e cinzas (Rostagno et al., 2000), estão relacionados aos ótimos valores de digestibilidade deste alimento, pois estes fatores estão geralmente relacionados a diminuição da digestibilidade (Bedford, 1995; Asp, 1996). Entretanto, um dos possíveis problemas para sua inclusão em rações deve-se justamente aos altos níveis de PD e ED, que devem limitar sua inclusão, pois, durante a larvicultura da tilápia, a sua exigência em PD é de cerca de $38,6 \%$ e cerca de $3800 \mathrm{kcal} / \mathrm{kg}$ de ED (Hayashi et al., 2002). 
Tabela 5 - Comparação dos valores dos CD da PB, EB e MS dos alimentos avaliados com os valores encontrados na literatura consultada

Table 5 - Comparison among the values of $C D$ of $C P, G E$ and DM of the evaluated feedstuffs and those reported by others authors

\begin{tabular}{|c|c|c|c|c|c|}
\hline \multirow{2}{*}{$\begin{array}{l}\text { Alimento } \\
\text { Feedstuff }\end{array}$} & \multicolumn{3}{|c|}{$\mathrm{CD}(\%)$} & \multirow{2}{*}{$\begin{array}{l}\text { Espécie } \\
\text { Specie }\end{array}$} & \multirow{2}{*}{$\begin{array}{c}\text { Referência } \\
\text { Reference }\end{array}$} \\
\hline & PB & $\mathrm{EB}$ & MS & & \\
\hline \multirow{10}{*}{$\begin{array}{l}\text { Farinha de } \\
\text { peixe } \\
\text { Fish meal }\end{array}$} & 90,66 & 89,53 & 87,63 & Tilápia do Nilo & Dados obtidos \\
\hline & 84,95 & 87,19 & 79,78 & Tilápia do Nilo & Furuya et al. (2001) \\
\hline & 90,26 & 90,40 & - & $\begin{array}{c}\text { Tilápia híbrida } \\
\text { (O.niloticus x } O \text {. aureus) }\end{array}$ & Degani et al. (1997a) \\
\hline & 96,17 & - & 90,48 & Tilápia do Nilo & Pezzato et al.(1988) \\
\hline & 86,49 & 79,78 & - & Tilápia do Nilo & Hanley (1987) \\
\hline & 71,07 & 93,43 & - & $\begin{array}{c}\text { Carpa comum } \\
\text { (Cyprinus carpio) }\end{array}$ & Degani et al. (1997b) \\
\hline & 80,23 & - & - & Rohu (Labeo rohita) & Hossain et al. (1997) \\
\hline & 95,87 & - & - & $\begin{array}{c}\text { Red drum } \\
\text { (Sciaenops ocellatus) }\end{array}$ & $\begin{array}{c}\text { McGoogan \& Reigh } \\
\text { (1996) }\end{array}$ \\
\hline & 95,80 & 94,10 & - & $\begin{array}{l}\text { Gilthead sea bream } \\
\text { (Sparus auratus) }\end{array}$ & Nengas et al. (1995) \\
\hline & 88,23 & 95,56 & 83,74 & $\begin{array}{c}\text { Striped bass híbrido } \\
\text { (M. saxalitis } x \text { M. chrysops) }\end{array}$ & Sullivan \& Reigh (1995) \\
\hline \multirow{8}{*}{$\begin{array}{l}\text { Farinha de } \\
\text { vísceras } \\
\text { Viscera meal }\end{array}$} & 82,03 & 72,02 & 62,21 & Tilápia do Nilo & Dados obtidos \\
\hline & 91,55 & 87,15 & - & $\begin{array}{l}\text { Tilápia híbrida } \\
\text { a }\end{array}$ & Degani et al. (1997a) \\
\hline & 73,87 & 58,77 & - & Tilápia do Nilo & Hanley (1987) \\
\hline & - & - & 91,60 & $\begin{array}{c}\text { Truta arco-íris } \\
\text { (Salmo gairdneri) }\end{array}$ & Sugiura et al. (1998) \\
\hline & - & - & 95,50 & $\begin{array}{c}\text { Salmão coho } \\
\text { (Oncorhynchus kisutch) }\end{array}$ & Sugiura et al. (1998) \\
\hline & 47,15 & 63,87 & - & $\begin{array}{c}\text { Carpa comum } \\
\text { (Cyprinus carpio) }\end{array}$ & Degani et al. (1997b) \\
\hline & 48,70 & 71,70 & 75,6 & $\begin{array}{c}\text { Red drum } \\
\text { (Sciaenops ocellatus) }\end{array}$ & Gaylord \& Gatlin (1996) \\
\hline & 81,8 & 80,30 & - & $\begin{array}{l}\text { Gilthead sea bream } \\
\text { (Sparus auratus) }\end{array}$ & Nengas et al. (1995) \\
\hline \multirow{5}{*}{$\begin{array}{l}\text { Glúten de } \\
\text { milho } \\
\text { Maize gluten }\end{array}$} & 97,61 & 93,52 & 91,01 & Tilápia do Nilo & Dados obtidos \\
\hline & 97,30 & - & 87,70 & $\begin{array}{c}\text { Truta arco-íris } \\
\text { (Salmo gairdneri) }\end{array}$ & Sugiura et al. (1998) \\
\hline & 91,9 & - & 88,00 & $\begin{array}{c}\text { Salmão coho } \\
\text { (Oncorhynchus kisutch) }\end{array}$ & Sugiura et al. (1998) \\
\hline & 90,00 & 79,70 & - & $\begin{array}{l}\text { Gilthead sea bream } \\
\text { (Sparus auratus) }\end{array}$ & Nengas et al. (1995) \\
\hline & 95,3 & 91,8 & 90,70 & $\begin{array}{c}\text { Truta arco-íris } \\
\text { (Salmo gairdneri) }\end{array}$ & Gomes et al. (1995) \\
\hline $\begin{array}{l}\text { Levedura } \\
\text { spray dried }\end{array}$ & 77,39 & $62,77(2708 *)$ & 58,68 & Tilápia do Nilo & Dados obtidos \\
\hline Spray dried yeast & 93,44 & $3601 *$ & 81,1 & Tilápia do Nilo & Barros et al. (1988) \\
\hline
\end{tabular}

${ }^{*} \mathrm{Kcal} / \mathrm{kg}$ de ED. 
A FP testada pode ser considerada uma boa fonte de proteínas para compor rações para a tilápia do Nilo. Este alimento apresentou ótimo CD das frações estudadas, o que denota boa qualidade. Porém, ao se formularem rações para esta espécie, deve-se dar atenção especial aos níveis de minerais, especialmente o fósforo, que, de acordo com Rostagno et al. (2000), situa-se em torno dos $3,0 \%$ daFPe a exigência da espécie varia de 0,8 a 1,0\% de fósforo total (NRC, 1993).

A FV estudada neste experimento apresentou-se como fonte protéica. Os valores regulares de $\mathrm{CD}$ da PB e a EB podem estar relacionados à inclusão de penas. O baixo CD da MS deve-se, além da presença de penas, ao alto conteúdo de cinzas deste alimento. Quanto à inclusão deste alimento à ração, para esta espécie, deve-se considerar o seu alto conteúdo em cinzas e principalmente o de gordura, que pode variar de 15,0 a 29,0\% (Degani et al, 1997b; Nengas et al. 1995). Meurer et al. (2002) afirmaram que níveis maiores de 3,0\% de gordura nas rações, para alevinos de tilápia do Nilo, diminuem seu crescimento e aumentam o depósito de gordura corporal.

Os baixos CD da PB, EB e MS da LS devem-se, no caso da $\mathrm{PB}$, à alta quantidade de nitrogênio não protéico (Butolo, 1997) e no caso da EB e MS, à alta percentagem de parede celular, cerca de 14,0 a 30,0\% (Assis, 1997). A parede celular é constituída principalmente de polissacarídeos não-amilaceos (Bach Knudsen, 2001), elementos que não são aproveitados eficientemente pela tilápia do Nilo, podendo atuar também como redutores de digestibilidade (Boscolo et al., 2002). Entretanto, de acordo com Meurer et al. (2000), a inclusão de até $6,0 \%$ deste alimento nas rações para alevinos de tilápia do Nilo, melhorou linearmente seu desempenho.

Além das diferenças em relação à composição química dos alimentos, outro fator que dificulta a comparação dos valores de CD com os encontrados na literatura é a variabilidade de metodologias empregadas. Hanley (1987) utilizou o nível de inclusão do alimento teste entre 82,0 e $90,0 \%$ e os valores do indicador no alimento foi feito a partir de amostras retiradas do estômago dos peixes. Pezzato et al. (1988a) e Barros et al. (1988) utilizaram a metodologia direta de coleta de fezes, com inclusão de 50,0\% do alimento teste (exceto a levedura de álcool) e como ração-referência foi utilizado farinha de carne variando o nível de inclusão do alimento-teste. Degani et al. (1997a) utilizaram $47,5 \%$ do ingrediente a ser testado, utilizando peixes adultos $(250 \mathrm{a} 400 \mathrm{~g}) \mathrm{e}$ coleta de fezes por extrusão. Já Boscolo et al. (2002) e Furuya et al. (2001) utilizaram a metodologia semelhante à aqui utilizada. Portanto, o estabelecimento de padrões para experimentos de digestibilidade seria bem-vindo, para evitar que a metodologia utilizada induza a erros de avaliação.

\section{Conclusões}

Há necessidade da determinação específica dos valores de digestibilidade de cada alimento para cada espécie animal, visando a formulação de rações a serem utilizadas na determinação de suas exigências nutricionais. Isto é evidente, tendo em vista justamente as diferenças encontradas nos valores dos nutrientes e energia bruta para os mesmos, o que foi verificado neste experimento para a levedura, glúten de milho, farinha de peixe e farinha de vísceras de aves, podendo resultar em desperdício na utilização dos alimentos, provocando menor desempenho na produtividade animal.

\section{Literatura Citada}

AKSNES, A.; OPSTVEDT, J. Content of digestible energy in fish feed ingredients determined by the ingredient-substitution method. Aquaculture, v.161, p.45-53, 1998.

ALCESTE, C.; JORRY, D. Análisis de las tendencias actuales en comercialización de tilapia en los Estados Unidos de Norteamérica y la Union Europea. In: CONGRESSO SULAMERICANO DE AQUICULTURA, 1., 1998, Recife. Anais... Recife: SIMBRAQ, 1998. p.349.

ASP, N.G. Dietary carbohydrates: classification by chemistry and physiology. Food Chemistry, v.57, n.1, p.9-14, 1996.

ASSIS, E.M. Componentes da parede celular de leveduras: proteínas e polissacarídeos de interesse das indústrias farmacêuticas e de alimentos. In: PRODUÇÃO DE BIOMASSA DE LEVEDURA: UTILIZAÇÃO EM ALIMENTAÇÃO HUMANA E ANIMAL, 1997, Campinas. Anais... Campinas: ITAL, 1997. p.41.

BACH KNUDSEN, K.E. The nutricional significance of "dietary fiber" analysis. Animal Feed Science and Technology, v.90, n.3, p.3-20, 2001

BARROS, M.M.; PEZZATO, L.E.; SILVEIRA, A.C. et al. Digestibilidade aparente de fontes alimentares alternativas pela tilápia do Nilo Oreochromis niloticus. In: SIMPÓSIO BRASIEIRO DE AQUICULTURA, 5., 1988, Florianópolis. Anais... Florianópolis: SIMBRAQ, 1988. p.428.

BEDFORD, M.R. Mechanism of action and potential environmental benefits from the use of feed enzymes. Animal Feed Science and Technology, n.53, p.145-155, 1995.

BOOTH, M.A.; ALLAN, G.L.; FRANCES, J. et al. Replacement of fish meal in diets for Australian silver perch, Bidyanus bidyanus IV. Effects of de-hulling and protein concentration on digestibility of grain legumes. Aquaculture, v.196, p.67-85, 2001. 
BOSCOLO, W.R.; HAYASHI, C.; MEURER, F. et al. Farinhas de peixe, carne e ossos, vísceras e crisálida como atractantes em dietas para alevinos de tilápia do Nilo (Oreochromis niloticus). Revista Brasileira de Zootecnia, v.30, n.5, p.1397-1402, 2001.

BOSCOLO, W.R.; HAYASHI, C.; MEURER, F. Digestibilidade aparente da energia e proteína bruta de alguns alimentos pela tilápia do Nilo (Oreochromis niloticus). Revista Brasileira de Zootecnia, v.31, n.2, p.539-545, 2002.

BOYD, C. Water quality in ponds for aquaculture. London: Birmingham Publishing Co, 1990. 482p.

BUTOLO, J.E. Uso da levedura desidratada em alimentação animal: propriedades, custo relativo a outras formas de nutrientes. In: PRODUÇÃO DE BIOMASSA DE LEVEDURA: UTILIZAÇÃO EM ALIMENTAÇÃO HUMANA E ANIMAL, 1997, Campinas. Anais...Campinas: ITAL, 1997. p.70.

CARTER, C.G.; BRANSDEN, R.J.; Van BARNEVELD, R.J.; et al. Alternative methods for nutrition research on the southern bluefin tuna, Thunnus maccoyii, in vitro. Aquaculture, v.179, p.57-70, 1999.

DE LA NOÜE, J.; CHOUBERT, G. Digestibility in rainbow trout: comparison of the direct and indirect methods of measurement. The Progressive Fish Culturist, v.48, p.190-195, 1986.

DEGANI, G.; REVACH, A. Digestive capabilities of three commensal fish species: carp, Cyprinus carpio L., tilapia, Oreochromis aureus X O. niloticus, and African catfish, Clarias gariepinus (Burchel 1822). Aquatic Fisheries Management, v.22, p.397-403, 1991.

DEGANI, G.; VIOLA, S.; YEHUDA, Y. Apparent digestibility of protein and carbohydrate in feed ingredients for adult tilapia (Oreochromis aureus X O. niloticus). Bamidgeh, v.49, n.3, p.115-123, 1997a.

DEGANI, G.; VIOLA, S.; YEHUDA, Y. Apparent digestibility coefficient of protein for carp, Cyprinus carpio L. Aquaculture Research, v.28, n.8, p.23-28, 1997b.

DIMES, L.E.; HAARD, N.F. Estimation of protein digestibility - I. Development of an in vitro method for estimating protein digestibility in salmonid (Salmo gairdneri). Comparative Biochemistry and Physiology, v.108, p.349-362, 1994.

EL-SAYED, A.F.M. Alternative dietary protein sources for farmed tilapia, Oreochromis spp. Aquaculture, v.179, p.149-168, 1999.

FURUYA, W.M.; PEZZATO, L.E.; MIRANDA, E.C. et al. Coeficiente de digestibilidade aparente da energia e nutrientes de alguns ingredientes pela tilápia do Nilo (Oreochromis niloticus). In: REUNIÃO ANUAL DA SOCIEDADE BRASILEIRA DE ZOOTECNIA, 38., 2001, Piracicaba. Anais...Piracicaba: Sociedade Brasileira de Zootecnia, 2001. p.1407-1409.

GAYLORD, T.G.; GATLIN III, D.M. Determination of various feedstuffs for red drum (Sciaenops ocellatus). Aquaculture, v.139, p.303-314, 1996.

GOMES, F.E.; REMA, P.; KAUSHIK, S.J. Replacement of fish meal by plant proteins in the diet of rainbow trout (Oncorhynchus mykiss): digestibility and growth performance. Aquaculture, v.130, p.177-186, 1995.

HANLEY, f. The digestibiliy of foodstuffs and the effects of feeding selectivity on digestibility determinations in tilapia, Oreochromis niloticus (L). Aquaculture, v.66, p.163-179, 1987.
HARDY, R.W. Alternate protein sources for salmon and trout diets. Animal Feed Science Technology, v.59, p.71-80, 1996.

HAYASHI, C. Breves considerações sobre as tilápias. In: RIBEIRO, R.P.; HAYASHI, C; FURUYA, W.M. (Eds.). Curso de piscicultura - criação racional de tilápias. 1.ed. Maringá, 1995. p.4.

HAYASHI, C.; BOSCOLO, W.R.; SOARES, C.M. et al. Uso de diferentes graus de moagem dos ingredientes em dietas para tilápia do Nilo (Oreochromis niloticus L.) na fase de crescimento. Acta Scientiarum, v.21, n.3, p.733-737, 1999.

HAYASHI, C.; BOSCOLO, W.R.; SOARES, C.M. et al. Exigência de proteína digestível para larvas de tilápia do Nilo no período de reversão sexual. Revista Brasileira de Zootecnia, v.31, n.2, p.823-828, 2002.

HOSSAIN, M.A.; NAHAR, N.; KAMAL, M. Nutrient digestibility coefficients of some plant and animal proteins for rohu (Labeo rohita). Aquaculture, 151, p.37-45, 1997.

KIKUCHI, K. Use of deffated soybean meal as a substitute for fish meal in diets of Japanese flounder (Paralichthys olivaceus). Aquaculture, v.179, p.3-11, 1999.

KIMURA, F.T.; MILLER, V.L. Improved determination of chromic oxide in cal feed and feces. Journal of Agricultural Foodstuffs Chemistry, v.5, n.2, p.216. 1957.

KUBITZA, F. Nutrição e alimentação dos peixes. Piracicaba: Escola Superior de Agricultura Luiz de Queiroz, 1997. 74p.

LOVSHIN, L.L. Tilápia farming: a growing worldwild aquaculture industry. In: SIMPÓSIO SOBRE MANAJO E NUTRIÇÃO E PEIXES, 1., 1997, Piracicaba. Anais...Piracicaba: Colégio Brasileiro de Nutrição Animal, 1997. p.137.

LOVSHIN, L.L.; CYRINO, J.E.P. Status of commercial fresh water fish culture in Brazil.. In: SIMPÓSIO SOBRE MANAJO E NUTRIÇÃO E PEIXES, 2., 1998, Piracicaba. Anais...Piracicaba: Colégio Brasileiro de Nutrição Animal, 1998. p.1.

MASUMOTO, T.; RUCHIMAT, T.; ITO, Y. et al. Amino acid availability values for several protein sources for yellowtail (Seriola quinqueradiata). Aquaculture, v.146, p.109-119, 1996.

MCGOOGAN, B.B.; REIGH, R.C. Apparent digestibility of selected ingredients in red drum (Sciaenops ocellatus) diets. Aquaculture, v.141, p.233-244, 1996.

MEURER, F.; HAYASHI, C.; SOARES, C.M. et al. Utilização de levedura spray dried na alimentação de alevinos de tilápia do Nilo (Oreochromis niloticus L.). Acta Scientiarum, v.22, n.2, p.479-484, 2000.

MEURER, F.; HAYASHI, C.; BOSCOLO, W.R. et al. Lipídeos na alimentação de alevinos revertidos de tilápia do Nilo (Oreochromis niloticus L.). Revista Brasileira de Zootecnia, v.31, n.2, p.566-573, 2002.

MORALES, A.E.; CARDENETE, G.; SANZ, A. et al. Re-evaluation of crude fiber and acid-insoluble ash as intermarkers, alternative to chromic oxide, in digestibility studies with rainbow trout (Oncorhynchus mykiss). Aquaculture, v.179, p.71-79, 1999.

MUKHOPADHYAY, N.; RAY, A.K. The apparent total and nutrient digestibility of sal seed (Shorea robusta) meal in rohu, Labeo rohita (Hamilton), fingerlings. Aquaculture Research, v.28, p.683-689,1997.

NATIONAL RESEARCH COUNCIL - NRC. Nutrient requirements of warmwater, fishes and shellfishes: nutrient requirements of domestic animals. Washington, D.C.: $1993.114 \mathrm{p}$. 
NENGAS, I.; ALEXIS, M.N.; DAVIES, S.J. et al. Investigation to determine digestibility coefficients of various raw materials in diets for gilthead sea bream, Sparus auratus L. Aquaculture Research, v.26, p.185-194, 1995.

OLIVEIRA, A.C.B.; CANTELMO, O.A.; PEZZATO, L.E. et al. Coeficiente de digestibilidade aparente da torta de dendê e do farelo de coco em pacú (Piaractus mesopotamicus). Revista Unimar, v.19, n.3, p.897-903, 1997.

PACHECO, M.T.B. Levedura como fonte de proteína: extração, isolamento, propriedades nutritivas e funcionais. In: PRODUÇÃO DE BIOMASSA DE LEVEDURA: UTILIZAÇÃO EM ALIMENTAÇÃO HUMANA E ANIMAL, 1997, Campinas. Anais...Campinas: ITAL, 1997. p.5.

PEZZATO, L.E.; PEZZATO, A.C.; SILVEIRA, A.C. et al. Digestibilidade aparente de fontes protéicas pela tilápia do Nilo Oreochromis niloticus. In: SIMPÓSIO BRASIEIRO DE AQUiCUlTURA, 5., 1988, Florianópolis. Anais... Florianópolis: SIMBRAQ, 1988a. p. 373.

PEZZATO, L.E.; BARROS, M.M.; PEZZATO, A.C.; et al. Parâmetros para determinação da digestibilidade aparente de alimentos através do método direto com tilápia do Nilo Oreochromis niloticus. In: SIMPÓSIO BRASIEIRO DE AQUiCultura, 5., 1988, Florianópolis. Anais... Florianópolis: SIMBRAQ, 1988b. p. 367.

POPMA, T.J.; PHELPS, R.P. Status report to commercial tilápia producers on monosex fingerling productions techniques. In: SIMPÓSIO SUL AMERICANO DE AQUICULTURA, 1., 1998, Recife. Anais... Florianópolis: SIMBRAQ, 1998. p.127.

REFSTIE, S.; SVIHUS, B.; SHEARER, K.D. et al. Nutrient digestibility in Atlantic salmon and broiler chickens related to viscosity and non-starch polysaccharide content in different soybean products. Animal Feed Science and Technology, v.79, p.331-345, 1999.

ROBAINA, L.; MOYANO,F.J.; IZQUIERDO, M.S. et al. Corn gluten and meat and bone meals as protein sources in diets for gilthead (Sparus aurata): Nutritional and histological implications. Aquaculture, v.157, p.347-359, 1997.

ROSSEL, C.E.V.Estudo de otimização de recuperação de biomassa em destilarias. In: PRODUÇÃ O DE BIOMASSA DE LEVEDURA: UTILIZAÇÃO EM ALIMENTAÇÃO HUMANA E ANIMAL, 1997, Campinas. Anais... Campinas: ITAL, 1997. p.59.
ROSTAGNO, H.S., ALBINO, L.F.T., DONZELE, J.L. et al. Tabelas Brasileiras para Aves e Suínos - Composição de Alimentos e Exigências Nutricionais. 1.ed. Viçosa, MG: Universidade Federal de Viçosa, 2000. 141p.

SADIKU, S.O.E.; JAUNCEY, K. Digestibility, apparent amino acid availability and waste generation potential of soybean flour: poultry meat meal blend based diets for tilapia, Oreochromis niloticus (L.), fingerlings. Aquaculture Research, v.26, p. 651-657, 1995.

SCAPINELLO, C.; FURLAN, A.C.; MOREIRA, I. et al. Utilização da levedura de recuperação (Saccharomyces $\mathrm{sp}$ ), seca pelo método spray-dry para coelhos em crescimento. Revista Unimar, v.18, n.3, p.587-598, 1996.

SCAPINELLO, C.; FURLAN, A.C.; OLIVEIRA, P.B. et al. Desempenho de coelhos em crescimento com levedura de recuperação (Saccharomyces sp), seca pelo método spraydry. Revista Unimar, v.19, n.3, p.913-921, 1997.

SIDDHURAJU, P.; BECKER, K. Preliminary nutritional evaluation of Mucuna seed meal (Mucuna pruriens var. utilis) in common carp (Cyprinus carpio L.): an assessment by growth performance and feed utilization. Aquaculture, v.196, p.105-123, 2001.

SILVA, D.J. Análise de alimentos (Métodos químicos e biológicos). Viçosa, MG: Universidade Federal de Viçosa, 1990. 166p.

SUGIURA, S.H.; DONG, F.M.; RATHBONE, C.K. et al. Apparent protein digestibility and mineral availabilities in various feed ingredients for salmonid feeds. Aquaculture, v.159, p.177-202, 1998.

SULLIVAN, J.A.; REIGH, R.C. Apparent digestibility of selected feedstuffs in diets for hybrid striped bass (Morone saxatilis X Morone chrysops). Aquaculture, v.138, p.313-322, 1995.

ZIMMERMANN, S.; JOST, H.C. Recentes avanços na nutrição de peixes: a nutrição por fases em piscicultura intensiva. In: SIMPÓSIO SOBRE MANEJO E NUTRIÇÃO DE PEIXES, 2., 1998, Piracicaba. Anais... Piracicaba: Colégio Brasileiro de Nutrição Animal, 1998. p.123. 